Check for updates

Cite this: RSC Adv., 2017, 7, 51978

Received 28th June 2017

Accepted 23rd October 2017

DOI: 10.1039/c7ra07160d

rsc.li/rsc-advances

\title{
Photo-induced orientation behaviors of
azobenzene liquid crystal copolymers for photonic \\ Photo-induced orientation behaviors of
azobenzene liquid crystal copolymers for photonic crystals $\uparrow$
}

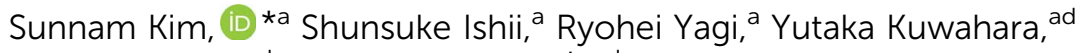 \\ Tomonari Ogatab $^{\mathrm{b}}$ and Seiji Kurihara*acd
}

\begin{abstract}
A certain wavelength of incident light is forbidden based on the optical periodicity related to the intervals and refractive indices of the comprising materials. For multi-bilayered films with periodicity, on-off switching of reflection is possible due to the presence or absence of a refractive index difference between two consisting films. Changes in the refractive index can be induced by stimuli-responsive orientation behaviors of liquid crystal (LC) molecules with birefringence. Azobenzene (Az) groups are employed for photo response and copolymerized with non-photo-responsive LC mesogen groups for cooperative orientation to improve light penetration by the dilution of Az concentration. LC mesogen groups are designed to have a high refractive index to improve the reflection contrast. The refractive indices and the orientation behaviors of the copolymer films are investigated. On-off switching of reflection for multi-bilayered films consisting of alternate Az-containing LC copolymers and poly vinyl alcohol is conducted using ultraviolet and visible light irradiation, and their reflection intensity and response speed are compared between the different LC mesogen types and molar ratios.
\end{abstract}

\section{Introduction}

In nature, such as in opal, neon tetra fish, peacock wings, and Morpho butterfly wings, structural coloration, that is, the reflection light by the optical periodic structure, can be found. The artificial periodic nanostructured-materials are called photonic crystals (PCs) and they have attracted considerable research interest for self-standing color reflective displays. It is a very suitable technology for paper-like displays attributed to low eye fatigue and low power consumption based on the lack of a necessity for a light source. ${ }^{1-7}$ Many researchers have studied the wavelength change based on responsible periodicity under external stimuli such as electrical or magnetic fields, ${ }^{8-10} \mathrm{pH}^{11-13}$ temperature, ${ }^{14,15}$ moisture and chemicals. ${ }^{15-17}$

In addition, we recently reported the photochemical on-off switching of the reflection intensity for multi-bilayered films as one dimensional PCs. ${ }^{18,19}$ This could be achieved by controlling the difference in the refractive indices of the laminate of two

${ }^{a}$ Graduate School of Science and Technology, 2-39-1 Kurokami, Kumamoto 860-8555, Japan.E-mail: sn-kim@kumamoto-u.ac.jp; kurihara@gpo.kumamoto-u.ac.jp; Fax: +81-96-342-3679; Tel: +81-96-342-3677

${ }^{b}$ Innovative Collaboration Organic Kumamoto University, 2-39-1 Kurokami, Kumamoto 860-8555, Japan

${ }^{c}$ Kumamoto Institute for PHOTO-Organics (PHOENICS), 3-11-38 Higashimachi, Higashi-ku, Kumamoto, 862-0901, Japan

${ }^{d} J S T$-CREST, Gobancho, Chiyoda-ku, Tokyo 102-0076, Japan

$\dagger$ Electronic supplementary information (ESI) available. See DOI: 10.1039/c7ra07160d films having different refractive indices overlapping one another. The reflectance, $R$, of the multi-bilayered films is given by the following equation for the normal incidence of light: ${ }^{20}$

$$
R=\left[\frac{1-\left(n_{\mathrm{H}} / n_{\mathrm{L}}\right)^{2 q}\left(n_{\mathrm{H}}^{2} / n_{\mathrm{S}}\right)}{1+\left(n_{\mathrm{H}} / n_{\mathrm{L}}\right)^{2 q}\left(n_{\mathrm{H}}^{2} / n_{\mathrm{S}}\right)}\right]^{2}
$$

where $n_{\mathrm{H}}$ and $n_{\mathrm{L}}$ are the high and low refractive indices of the stacked materials in each bilayer, respectively, $n_{\mathrm{S}}$ is the refractive index of the substrate and $q$ is the number of bilayers. From eqn (1), it can be observed that reflectance increases with increasing difference between $n_{\mathrm{H}}$ and $n_{\mathrm{L}}$. In contrast, the reflectance considerably decreased when $n_{\mathrm{H}}$ and $n_{\mathrm{L}}$ are nearly equal; therefore, an on-off switching of the reflection can be achieved by controlling the difference in the refractive indices of the stacked materials between the equivalent state and the non-equivalent state for $n_{\mathrm{H}}$ and $n_{\mathrm{L}}$.

Changes in the refractive index of the film can be induced by changes in the orientation states when incorporating liquid crystal (LC) molecules with birefringence. The Az group is one of superior light-sensitive materials and can induce reversible and stable molecular orientation behaviors in the polymeric films. For the multi-bilayered films laminated with alternate PVA films $\left(n_{\mathrm{PVA}}=1.5\right)$ and Az-containing LC polymer films, on-off switching of the reflection was achieved by remote control of the orientation states of the LC films with a refractive index change between 1.5 and 1.6. ${ }^{18,19}$ However, since the absorbance of the azobenzene chromophore is high, there is the problem that 
light penetration is interrupted in the films and the response for the on-off switching of the reflection is delayed.

To improve the light response efficiency across the entire film, the non-photo-responsive LC mesogen groups are employed because it is possible to dilute the $\mathrm{Az}$ chromophore concentration and to cooperatively change the orientation states. For multi-bilayered films consisting of Az copolymers with biphenyl groups such as the LC mesogen groups, the light response speed was faster than that of the $\mathrm{Az}$ homopolymer. ${ }^{21}$ However, the reflection intensity deteriorated due to the low refractive index of the biphenyl group as reflection intensity relied on the refractive index difference of composite materials.

In order to improve the reflection intensity, herein we attempted to find LC groups exhibiting high refractive indices as well as good cooperative orientation behavior. Since the dielectric constant increases with the long-conjugated system, molecules with the longer conjugated system exhibit higher refractive indices. This is based on the relational expression of $\varepsilon=n^{2}$, where $\varepsilon$ and $n$ represent the dielectric constant and refractive index, respectively. In addition, a Tolan group has been reported to increase the extraordinary refractive index with high conjugation along the molecular long axis, attributing to an increase of the average refractive index and birefringence. ${ }^{22-25,28-30}$ In this study, various LC mesogen groups with long conjugation on the molecular long axis such as Tolan, Schiff base, and stilbene groups were employed for Azcontaining copolymers and their refractive indices, and the photo-induced orientation behaviors were compared. In addition, for the multi-bilayered films composed of the Azcontaining copolymers and PVA, the photo-induced reflection behaviors were investigated in relation to their reflection intensity and light-response rate.

\section{Experimental}

\section{Synthesis and polymerization}

$\mathrm{Az}$ and LC mesogen monomers were synthesized according to the same method reported previously. ${ }^{26,27}$ The structures and purities of the monomers were identified by H-NMR (JEOL JNMEX400) and the melting point by polarizing microscopic observation (POM; Olympus BHSP polarizing microscope; Mettler FP80 and FP82 hot stage and controller) and elemental analysis (Yanaco MICRO CORDER JM 10) is as follows.

Azobenzene (Az): 6-[4-(4-methoxyphenylazo)phenoxy]hexylacrylate. ${ }^{1} \mathrm{H} \mathrm{H} \mathrm{NMR}\left(400 \mathrm{MHz}, \mathrm{CDCl}_{3} ; \delta, \mathrm{ppm}\right): 1.42-2.19(\mathrm{~m}$, $8 \mathrm{H}$, methylene); $3.89\left(\mathrm{~s}, 3 \mathrm{H}, \mathrm{ArOCH}_{3}\right) ; 4.00-4.10(\mathrm{t}, J=6.0 \mathrm{~Hz}$, $\left.2 \mathrm{H}, \mathrm{OCH}_{2}\right) ; 4.12-4.24\left(\mathrm{t}, J=6.0 \mathrm{~Hz}, 2 \mathrm{H}, \mathrm{OCH}_{2}\right) ; 6.08-6.18(\mathrm{~m}$, $\left.1 \mathrm{H}, \mathrm{CH}_{2}=\mathrm{CH}\right), 6.37-6.46,5.78-5.84\left(\mathrm{~d}, J=10.8 \mathrm{~Hz}, 2 \mathrm{H}, \mathrm{CH}_{2}=\right.$ $\mathrm{CH}$ ), 6.95-7.90 (m, 8H, aromatic) $\mathrm{C}_{22} \mathrm{H}_{26} \mathrm{~N}_{2} \mathrm{O}_{4}\left(M_{\mathrm{w}}\right.$ : 354.2); H; 6.85, C; 69.09, N; 7.32. Found (\%); H; 6.91, C; 69.05, N; 7.30. Yield: $10.8 \mathrm{~g}$ (53\%). Mp 95.5-96.7 ${ }^{\circ} \mathrm{C}$.

Stilbene (Stb): 6-(4-(4-methoxystyryl)phenoxy)hexyl acrylate. ${ }^{1} \mathrm{H} \mathrm{H}$ NMR (400 MHz, $\left.\mathrm{CDCl}_{3} ; \delta, \mathrm{ppm}\right): 1.4-2.0$ (m, 8H, methylene); $3.8\left(\mathrm{~s}, 3 \mathrm{H}, \mathrm{OCH}_{3}\right) ; 3.9\left(\mathrm{t}, J=5.9 \mathrm{~Hz}, 2 \mathrm{H}, \mathrm{PhOCH}_{2}\right) ; 4.2(\mathrm{t}$, $\left.J=6.3 \mathrm{~Hz}, 2 \mathrm{H}, \mathrm{COOCH}_{2}\right) ; 5.8,6.4\left(\mathrm{~d}, J=9.8,16.6 \mathrm{~Hz}, 2 \mathrm{H}, \mathrm{CH}_{2}=\right.$ $\mathrm{CH}) ; 6.1\left(\mathrm{~m}, 1 \mathrm{H}, \mathrm{CH}_{2}=\mathrm{CH}\right) ; 6.9(\mathrm{~m}, 1 \mathrm{H}, \mathrm{CH}=\mathrm{CH}) ; 6.8,7.4(\mathrm{~m}$, $8 \mathrm{H}$, aromatic) $\mathrm{C}_{24} \mathrm{H}_{28} \mathrm{O}_{4}\left(M_{\mathrm{w}}: 380.2\right) ; \mathrm{H} ; 7.42, \mathrm{C} ; 75.76, \mathrm{~N} ; 0.00$.
Found (\%); H; 7.28, C; 75.01, N; 0.14. Yield: 2.47 g (34.3\%). Mp $124-126{ }^{\circ} \mathrm{C}$.

Tolan (To): 6-(4-((4-methoxyphenyl)ethynyl)phenoxy)hexyl acrylate. ${ }^{1} \mathrm{H}$-NMR $\left(400 \mathrm{MHz}, \mathrm{CDCl}_{3} ; \delta\right.$, ppm): 1.4-2.0 (m, 8H, methylene); $3.8\left(\mathrm{~s}, 3 \mathrm{H}, \mathrm{OCH}_{3}\right) ; 3.9\left(\mathrm{t}, J=3.2 \mathrm{~Hz}, 2 \mathrm{H}, \mathrm{PhOCH}_{2}\right)$; $4.2\left(\mathrm{t}, J=6.6 \mathrm{~Hz}, 2 \mathrm{H}, \mathrm{COOCH}_{2}\right) ; 5.8,6.4(\mathrm{~d}, J=5.2,8.7 \mathrm{~Hz}, 2 \mathrm{H}$, $\left.\mathrm{CH}_{2}=\mathrm{CH}\right) ; 6.1\left(\mathrm{~m}, 1 \mathrm{H}, \mathrm{CH}_{2}=\mathrm{CH}\right) ; 6.8,7.4(\mathrm{~m}, 8 \mathrm{H}$, aromatic) $\mathrm{C}_{24} \mathrm{H}_{26} \mathrm{O}_{4}\left(M_{\mathrm{w}}: 378.2\right)(\%), \mathrm{H} ; 6.92$, C; 76.17, N; 0.00. Found (\%), $\mathrm{H} ; 6.94, \mathrm{C} ; 76.15$, N; 0.00. Yield: $1.50 \mathrm{~g}(47.8 \%) . T_{\mathrm{m}}: 55.0-57.5{ }^{\circ} \mathrm{C}$.

Tolan methyl (ToMe): 6-(4-((4-methoxyphenyl)ethynyl)-2methylphenoxy)hexyl acrylate. ${ }^{1} \mathrm{H}-\mathrm{NMR}\left(400 \mathrm{MHz}, \mathrm{CDCl}_{3} ; \delta\right.$, ppm): 1.4-2.0 (m, 8H, methylene); $2.2\left(\mathrm{~s}, 3 \mathrm{H}, \mathrm{PhCH}_{3}\right) ; 3.8(\mathrm{~s}, 3 \mathrm{H}$, $\left.\mathrm{OCH}_{3}\right) ; 3.9\left(\mathrm{t}, J=6.3 \mathrm{~Hz}, 2 \mathrm{H}, \mathrm{CH}_{2} \mathrm{OH}\right) ; 4.1(\mathrm{t}, J=8.8 \mathrm{~Hz}, 2 \mathrm{H}$, $\left.\mathrm{PhOCH}_{2}\right) ; 5.8,6.4\left(\mathrm{~d}, J=8.8,15.6 \mathrm{~Hz}, 2 \mathrm{H}, \mathrm{CH}_{2}=\mathrm{CH}\right) ; 6.1(\mathrm{~m}, 1 \mathrm{H}$, $\left.\mathrm{CH}_{2}=\mathrm{CH}\right) 6.7,(\mathrm{~d}, J=8.8 \mathrm{~Hz}, 1 \mathrm{H}$, aromatic) $6.8(\mathrm{~d}, J=8.8 \mathrm{~Hz}$, $2 \mathrm{H}$, aromatic); $7.3(\mathrm{~d}, J=8.8 \mathrm{~Hz}, 2 \mathrm{H}$, aromatic); $7.4(\mathrm{~d}, J=$ $8.8 \mathrm{~Hz}, 2 \mathrm{H}$, aromatic) $\mathrm{C}_{25} \mathrm{H}_{28} \mathrm{O}_{4}\left(M_{\mathrm{w}}: 392.2\right): \mathrm{H} ; 7.19, \mathrm{C} ; 76.50, \mathrm{~N}$; 0.00. Found (\%), H; 7.11, C; 76.40, N; 0.05. Yield: $3.97 \mathrm{~g}(65.6 \%)$. $T_{\mathrm{m}}: 58-61{ }^{\circ} \mathrm{C}$.

Schiff base (Schi): 6-(4-((4-methoxyphenyl)imino)methyl) phenoxy)hexyl acrylate. ${ }^{1} \mathrm{H}-\mathrm{NMR}\left(400 \mathrm{MHz}, \mathrm{CDCl}_{3} ; \delta, \mathrm{ppm}\right): 1.4-$ $1.8\left(\mathrm{~m}, 8 \mathrm{H}\right.$, methylene); $3.8\left(\mathrm{~s}, 3 \mathrm{H}, \mathrm{OCH}_{3}\right) ; 4.0(\mathrm{t}, J=6.3 \mathrm{~Hz} 2 \mathrm{H}$, $\left.\mathrm{CH}_{2} \mathrm{OH}\right) ; 4.1$ (t, $\left.J=6.8 \mathrm{~Hz} 2 \mathrm{H}, \mathrm{PhOCH}_{2}\right) ; 5.9,6.3$ (d, $J=9.8$, $\left.17.6 \mathrm{~Hz} 2 \mathrm{H}, \mathrm{CH}_{2}=\mathrm{CH}\right) ; 6.1\left(\mathrm{~m}, 1 \mathrm{H}, \mathrm{CH}_{2}=\mathrm{CH}\right) 6.9(\mathrm{~d}, J=8.8 \mathrm{~Hz}$ $2 \mathrm{H}$, aromatic); 7.0 (d, $J=8.8 \mathrm{~Hz} 2 \mathrm{H}$, aromatic); $7.2(\mathrm{~d}, J=8.8 \mathrm{~Hz}$ $2 \mathrm{H}$, aromatic); 7.8 (d, $J=8.8 \mathrm{~Hz} 2 \mathrm{H}$, aromatic) $8.5(\mathrm{~s}, 1 \mathrm{H}, \mathrm{CHN})$; $\mathrm{C}_{23} \mathrm{H}_{27} \mathrm{NO}_{4}\left(M_{\mathrm{w}}: 381.2\right): \mathrm{H} ; 7.13, \mathrm{C} ; 72.42, \mathrm{~N} ; 3.67$. Found (\%); $\mathrm{H}$; 7.15, C; 76.35, N; 3.70. Yield: $3.0 \mathrm{~g}(42.7 \%) . T_{\mathrm{m}}: 82-85{ }^{\circ} \mathrm{C}$.

\section{Polymerization}

Polymerizations were carried out as follows; first, $1.5 \mathrm{~g}$ of two monomers with various molar ratios (Az group : LC mesogen group $=10: 0,8: 2,7: 3,5: 5$, and $3: 7)$ was dissolved in $15 \mathrm{ml}$ of dimethyl formamide in a glass tube, and $15 \mathrm{mg}(0.06 \mathrm{mmol})$ of 2,2'-azobisisobutylonitrile was also added to the solution. After purging with nitrogen, the tube was sealed and shaken in a water bath at $60{ }^{\circ} \mathrm{C}$ for $48 \mathrm{~h}$. The reaction mixture was poured into excess methanol. Then the precipitated product was collected and dissolved in tetrahydrofuran (THF). After repeating this reprecipitation cycle several times, the produced copolymers were collected and dried under vacuum.

\section{Preparation of multi-bilayered films}

Multi-bilayered films were prepared according to previous reports. ${ }^{18,19,21}$ Az-containing copolymers were dissolved in cyclohexanone at $4.5 \mathrm{wt} \%$ and PVA was dissolved in water at $2.5 \mathrm{wt} \%$. The solutions were spin coated at $3000 \mathrm{rpm}$ on a glass substrate alternately and repeatedly, and 20-bilayered films were prepared. The thickness of Az100 and PVA was $95 \mathrm{~nm}$ and $90 \mathrm{~nm}$, respectively, from a surface profiler (Dektak-150, ULVAC). The thickness of the 20-bilayered films was measured by atomic force microscopy (AFM, Agilent 5500) and field emission scanning electron microscopy (FE-SEM, Hitachi SU-8000) (Fig. S12†). 


\section{Characterization}

The thermal properties of the polymers were examined by means of differential scanning calorimetry (DSC; Seiko DSC5020). The scan rate for the DSC measurements was $10{ }^{\circ} \mathrm{C} \mathrm{min}^{-1}$. Molecular weight was determined by gel permeation chromatography (GPC; Jasco 870-UV detector at $254 \mathrm{~nm}$, Shodex KF-804L column, THF as eluent). The copolymerization ratio was determined by UV-vis spectroscopy (Shimazu UV1600PC). An ultrahigh pressure mercury lamp with a heat cut filter (NAF-50S-50H) was used as a light source (USHIO SX-UI $500 \mathrm{H})$. UV light $\left(\lambda=365 \mathrm{~nm}, 8 \mathrm{~mW} \mathrm{~cm}^{-2}\right)$ and visible light $\left(\lambda=436 \mathrm{~nm}, 60 \mathrm{~mW} \mathrm{~cm}{ }^{-2}\right)$ were used with filters Sigma UTVAF35U and Sigma SCF-50s-42L, respectively. Refractive indices of the copolymer films were calculated by ellipsometry (Spectrum Ellipsometer FE-5000s, Otsuka Electronics Co., Ltd.) with the sodium D line at $589.3 \mathrm{~nm}$.

\section{Results and discussion}

With the Az group and LC mesogen groups such as stilbene (Stb), Schiff base (Schi), Tolan (To), and Tolan methyl (ToMe) groups, copolymers were prepared at various molar ratios of the LC groups to the Az group, as described in Table 1. Az100 represents the Az homopolymer. The Az-containing copolymers are abbreviated as AzStb, AzSchi, AzTo, and AzToMe. The numbers in the abbreviations indicate the molar ratio of the $\mathrm{Az}$ to the LC groups. Their molecular structures are shown in Fig. 1.

The average refractive indices of the copolymers in random orientation states were evaluated by ellipsometry measurements and the results are summarized in Fig. 2. The refractive indices of AzToMe, AzTo and AzStb were greater than or similar to that of Az100 (1.612). In contrast, the refractive indices of AzSchi were lower than that of Az100. The reason for the nonmonotonous behavior of the refractive index is not clear at present.

The phase transition temperatures of the copolymers were estimated by DSC measurements and the LC phases were confirmed by POM. The phase transition temperatures are summarized in Table 2. All the copolymers exhibited both smectic and nematic LC phases. However, for AzStb55 and

Table 1 Copolymerization conditions with molar ratios of Az and LC mesogen groups with the copolymer abbreviations

\begin{tabular}{llllll}
\hline \multirow{2}{*}{ LC mesogen } & $\begin{array}{l}\text { Az } \\
\text { (Loading ratio) }\end{array}$ & $\begin{array}{l}\text { LC mesogen } \\
\text { (Content ratio) }\end{array}$ & Sample name \\
\hline \multirow{2}{*}{ Stilbene } & 7 & 3 & 7 & 3 & AzStb73 \\
& 5 & 5 & 5 & 5 & AzStb55 \\
\multirow{3}{*}{ Schiff } & 3 & 7 & 2 & 8 & AzStb28 \\
& 7 & 3 & 7 & 3 & AzSchi73 \\
Tolan & 5 & 5 & 5 & 5 & AzSchi55 \\
& 3 & 7 & 3 & 7 & AzSchi37 \\
& 7 & 3 & 8 & 2 & AzTo82 \\
Tolan methyl & 8 & 2 & 7 & 3 & AzTo73 \\
& 7 & 5 & 4 & 6 & AzToMe91 \\
& 3 & 7 & 9 & 1 & AzToMe64
\end{tabular}

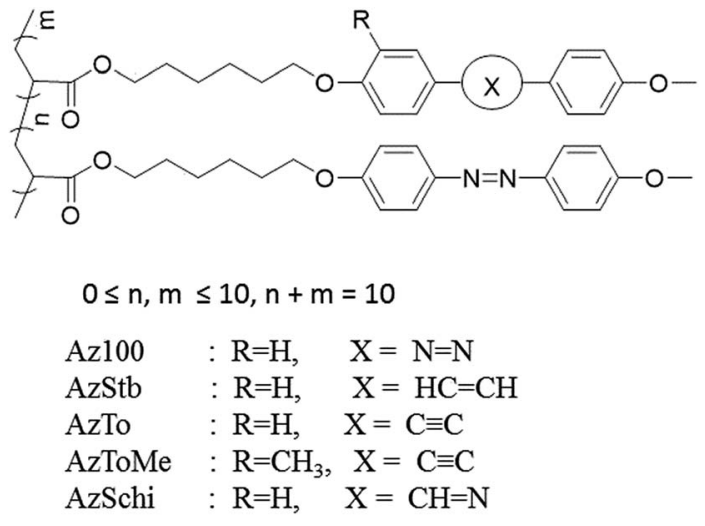

Fig. 1 Schematic of the molecular structures of the copolymers.

AzStb28 with higher molar ratios of the Stb group, the phase transition temperatures were not clearly observed. As shown in Fig. 3, the glass transition temperatures $\left(T_{\mathrm{g}}\right)$ of the copolymers decreased compared to that of Az100, except for the $T_{\mathrm{g}}$ of AzStb. The $T_{\mathrm{g}}$ of AzStb73 was estimated to be $66^{\circ} \mathrm{C}$, which was slightly higher than that of Az100. $T_{\mathrm{g}}$ is considered to be an important factor for orientation behaviors of polymers.

Photo-response isomerization behaviors were investigated in THF solution (Fig. S1 $\dagger$ ). For the UV-vis absorption spectra, the absorption bands at $360 \mathrm{~nm}$ and $450 \mathrm{~nm}$ corresponded to the $\pi-\pi^{*}$ transition and the $n-\pi^{*}$ transition, respectively, of the $\mathrm{Az}$ group. The changes in the absorption spectra based on trans-cis isomerization behavior were observed by irradiation of UV light (365 $\mathrm{nm}, 8 \mathrm{~mW} \mathrm{~cm}^{-2}$ ) and visible light (436 nm, $60 \mathrm{~mW} \mathrm{~cm}^{-2}$ ). It was observed that using UV light, the absorbance decreased at $365 \mathrm{~nm}$ and increased at $450 \mathrm{~nm}$, whereas using $436 \mathrm{~nm}$ visible light, reverse behaviors were observed. These changes were similar and reversible for all the samples, although the absorption bands of the Stb and Schi groups were partially overlapped with the $\pi-\pi^{*}$ transition absorption bands of the $\mathrm{Az}$ groups. Therefore, it was demonstrated that the photoresponsive orientation behavior of the $\mathrm{Az}$ group occurred stably even when the mesogen groups coexisted.

For the thin films prepared using the spin-coating method, the initial states were in random orientation states. The orientation states could be controlled by irradiation of $365 \mathrm{~nm}$, $436 \mathrm{~nm}$, and $546 \mathrm{~nm}$ UV-vis light, as shown in Fig. 4. Molar fractions of cis-isomers in each orientation state were respectively estimated to be 94\%, 15\%, and 1\% (supported by Fig. S8 and $\mathrm{S} 9 \dagger$ ). At $436 \mathrm{~nm}$ visible light, the Az units have absorption bands of both the cis and trans isomers and thus they can undergo repeated cis-trans isomerization. Then, the direction of alignment depends on the incident light direction due to the photo-orientation process, which is induced by anisotropic light absorption of trans-azobenzene fragments and subsequent rearrangement of the orientation structure of the material. ${ }^{31-38}$ Therefore, an out-of-plane orientation can be induced by normal incident light of $436 \mathrm{~nm}$ for the thin films. For $365 \mathrm{~nm}$ UV light, cis isomers are generated and the orientation state can be destroyed. Consequently, a random state is induced. Using 


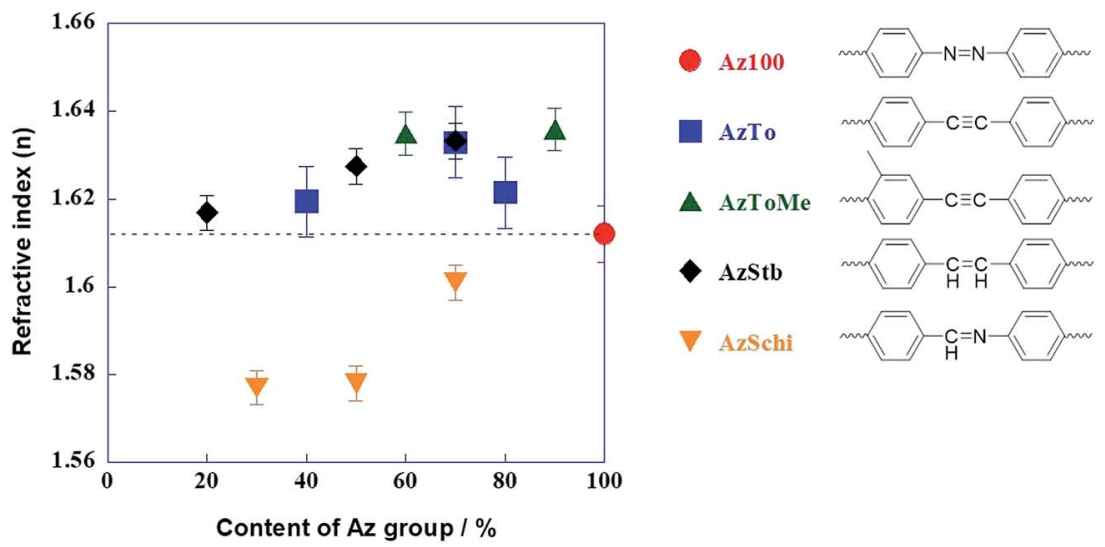

Fig. 2 Refractive indices of the copolymers with various molar ratios of the Az groups.

Table 2 Summary of the molecular weights and phase transition temperatures of the copolymers ${ }^{a}$

\begin{tabular}{llll}
\hline Abbreviation & $M_{\mathrm{n}}$ & $M_{\mathrm{w}} / M_{\mathrm{n}}$ & Phase transition temperature $\left[{ }^{\circ} \mathrm{C}\right]$ \\
\hline Az100 & 7500 & 1.23 & G 61 S 99 N 139 I \\
AzTo82 & 6800 & 1.57 & G 48 S 84 N 127 I \\
AzTo73 & 6700 & 1.35 & G 52 S 78 N 127 I \\
AzTo46 & 7600 & 1.55 & G 45 S 74 N 123 I \\
AzToMe91 & 7000 & 1.43 & G 53 S 69 N 124 I \\
AzToMe64 & 7800 & 1.41 & G 28 S 47 N 113 I \\
AzStb73 & 13500 & 2.32 & G 66 S 81 N 105 I \\
AzStb55 & 10500 & 2.26 & - \\
AzStb28 & 10500 & 1.71 & - \\
AzSchi73 & 9200 & 1.41 & G 53 S 102 N 139 I \\
AzSchi55 & 4900 & 1.22 & G 50 S 69, 103 N 130 I \\
AzSchi37 & 4700 & 1.21 & G 44 S 65, 102 N 125 I
\end{tabular}

$a{ }^{*} M_{\mathrm{n}}$ and $M_{\mathrm{w}} / M_{\mathrm{n}}$ are measured by GPC. ${ }^{* *} \mathrm{G}, \mathrm{S}, \mathrm{N}$ and I respectively present glass transition temperature, smectic phase, nematic phase and isotropic phase.

the subsequent $546 \mathrm{~nm}$ visible light, the isomerization behavior from the cis to trans isomers is conducted and thus the random orientation state with the trans isomers can be induced.

The orientation states of the films induced by irradiation of light were evaluated by the changes in the absorption spectra (Fig. S3 and S4 $\dagger$ ). For light at $436 \mathrm{~nm}, \pi-\pi *$ transition absorption bands of the Az groups and LC groups at $360 \mathrm{~nm}$ and $300 \mathrm{~nm}$ decreased. When the films were horizontally tilted $40^{\circ}$ to the plane normal to the monitoring light, anisotropic absorption spectra were observed for the vertically and horizontally polarized directions on the film, as shown in Fig. 5. In addition, eight patterns were observed in their polar graphs after irradiation by $436 \mathrm{~nm}$ visible light. Therefore it was demonstrated that out-of-plane orientation was induced. By irradiation by $365 \mathrm{~nm}$ UV light, absorbance at $300 \mathrm{~nm}$ and $450 \mathrm{~nm}$ increased. It was demonstrated that cis isomers of $\mathrm{Az}$ groups were generated and alignment of LC mesogen groups was destroyed, which led to a random orientation state. Subsequently, by irradiation by $546 \mathrm{~nm}$ visible light, absorbance at $360 \mathrm{~nm}$ increased and absorbance at $450 \mathrm{~nm}$ decreased,

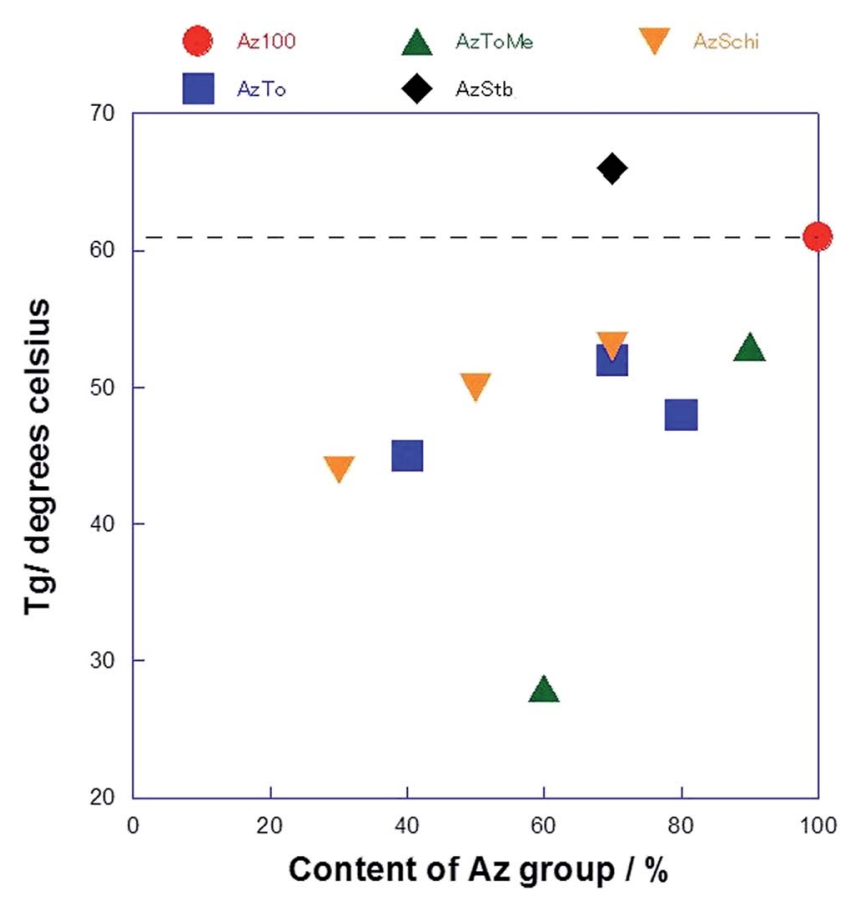

Fig. $3 T_{\mathrm{g}}$ of the copolymers with various molar ratios of the Az groups.

indicating cis to trans isomerization of the Az groups. From the isotropic absorbance, it was assumed that trans isomers of the Az group were randomly aligned.

The out-of-plane orientation states were evaluated using the order parameter $(S)$ of the Az groups. ${ }^{39} S$ was calculated with absorbance using the following eqn (2), when the films were horizontally tilted $40^{\circ}$ to the plane normal to the monitoring light:

$$
S=\frac{A_{\|}-A_{\perp}}{A_{\|}+2 A_{\perp}}
$$

where $A_{\|}$and $A_{\perp}$ are the polarized absorbances in the horizontal and vertical directions, respectively, for the plane normal to the monitoring light for the maximum wavelength $\left(\lambda_{\max }\right)$ of the $\mathrm{Az}$ group. 


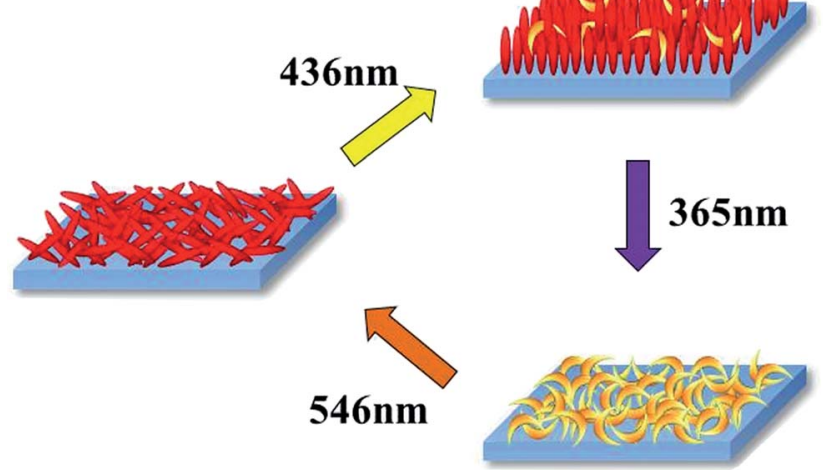

Fig. 4 Schematic of the orientation states of the films after irradiation by UV-vis light at $365 \mathrm{~nm}, 436 \mathrm{~nm}$, and $546 \mathrm{~nm}$.

For the thin films, the $S$ values with light of $365 \mathrm{~nm}$, $436 \mathrm{~nm}$, and $546 \mathrm{~nm}$ were compared, as shown in Fig. 6. For the random orientation states before irradiation of light, $S=0$. With $436 \mathrm{~nm}$ visible light, $S$ of Az100 increased to 0.6 in the out-of-plane orientation state. $S$ of the copolymers was lower than that of Az100. For AzStb, especially, the out-ofplane orientation state was hardly induced by light irradiation, presumably due to a high $T_{\mathrm{g}}$, as mentioned above. Finally, using UV light of $365 \mathrm{~nm}$ following visible light of

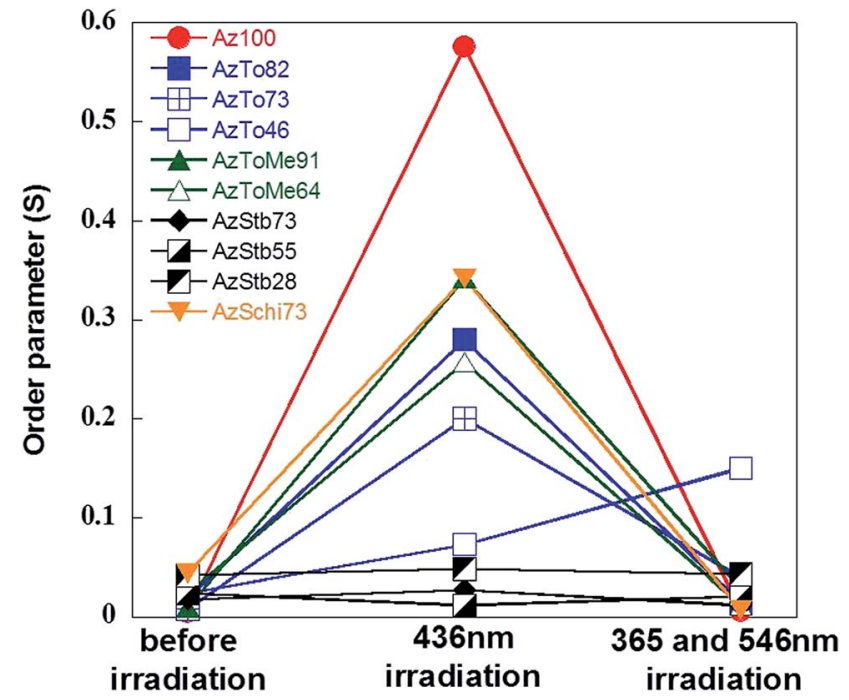

Fig. 6 The changes in $S$ for the films before and after light irradiation by $436 \mathrm{~nm}$ visible light, and $365 \mathrm{~nm}$ UV light following $546 \mathrm{~nm}$ visible light.

$546 \mathrm{~nm}$, random orientation states were induced and $S$ approached 0 .

For the multi-bilayered films comprising alternate Azcontaining films and PVA films, the photo-responsive speeds
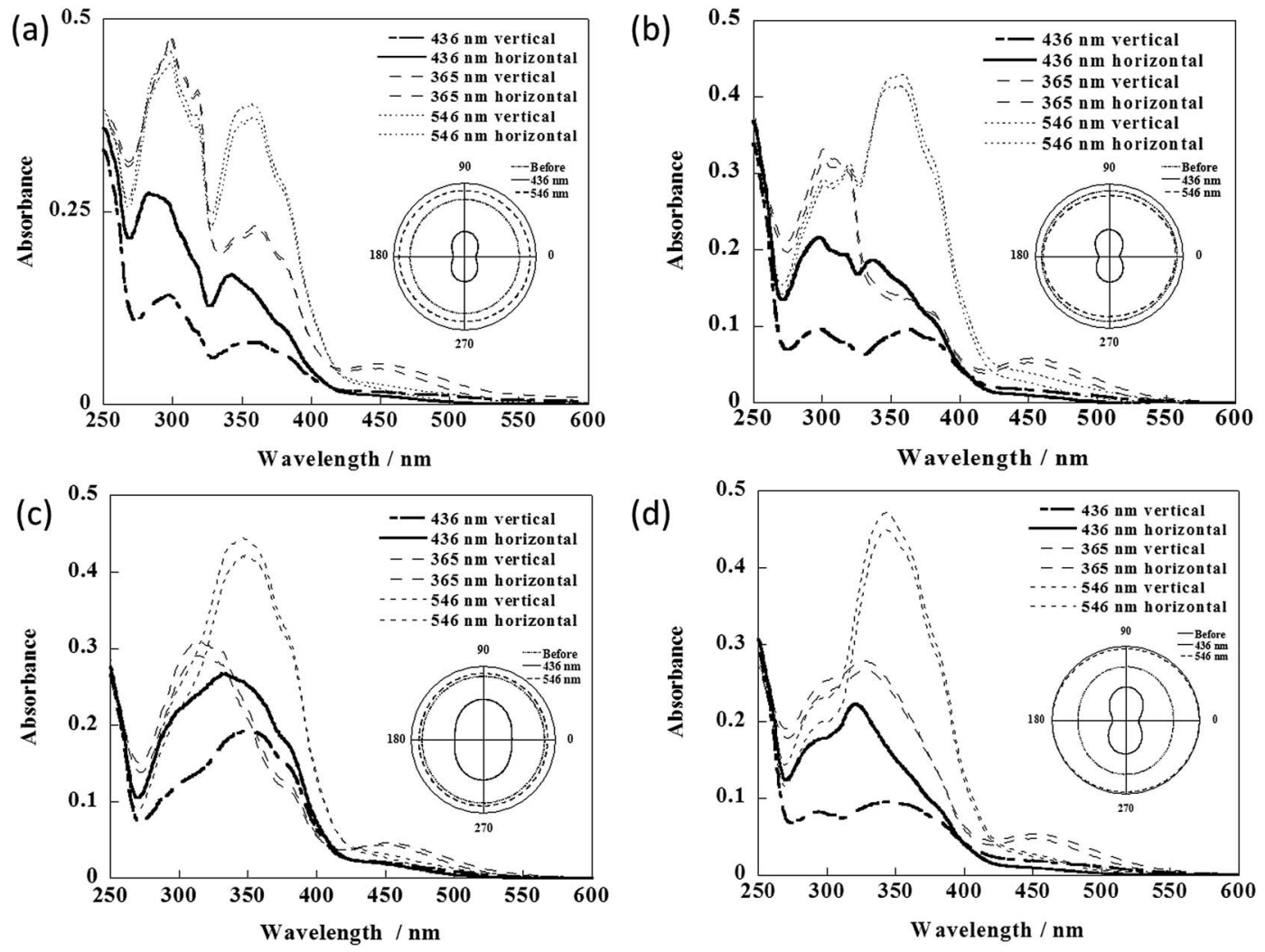

(d)

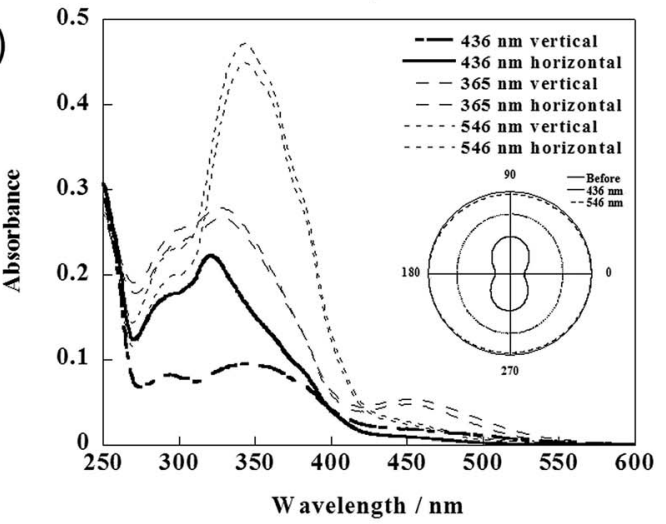

Fig. 5 The vertical and horizontal polarized absorption spectra of the AzTo82 (a), AzToMe91 (b), AzStb73 (c), and AzSchi73 (d) films after irradiation by $436 \mathrm{~nm}, 365 \mathrm{~nm}$, and $546 \mathrm{~nm}$ light for the plane normal to the monitoring light. The films were horizontally tilted $40^{\circ}$ to the plane normal to the monitoring light. The polar plots for the $\lambda_{\max }$ of the Az group are shown in the inset. 
for on-off switching of the reflection intensity were compared, as shown in Fig. 7. For $436 \mathrm{~nm}$ visible light, the reflection for all films decreased. For copolymers of AzTo82 and AzToMe91, the response speed of reflection was faster than that of Az100. It was assumed that out-of-plane orientation behaviors in the multibilayered films were improved by copolymerization with To and ToMe groups, possibly due to their lower $T_{\mathrm{g}}$ than that of Az100. On the other hand, the photo-response speed of reflection of AzSchi73 was slower than that of Az100 even though it has a lower $T_{\mathrm{g}}$. This is attributed to the surface energy depending on the hydrophobicity of LC mesogen groups when sandwiched by hydrophilic PVA films.

In order to estimate the hydrophobicity of LC molecules, dipole moments and the partition coefficient $(\log P)$ were calculated using Spartan'14 (Wavefunction, Inc.) with the B3LYP/6-31G* method. For Az, Schi, and To groups they were respectively estimated to be 0 Debye, 1.24 Debye, and 0 Debye for dipole moments; and 4.22, 3.65, and 3.72 for $\log P$. Consequently, a Schi group exhibiting higher polarity is relatively less hydrophobic. Therefore, AzSchi films sandwiched by PVA films are less preferable for out-of-plane orientation compared with the other copolymers, based on higher surface energy. This is supported by the experimental results of thermally induced out-of-plane orientation behaviors. When AzTo73 and AzSchi73 were annealed at $70{ }^{\circ} \mathrm{C}$, their $S$ values for out-of-plane orientation were respectively estimated to be 0.73 and 0.34. S of AzSchi73 was lower than that of AzTo73, as expected.

On the other hand, for $365 \mathrm{~nm}$ UV light, reflection for all films increased. The light response of AzToMe91 was faster than that of Az100 and other copolymers, indicating improvement of random orientation behavior attributed to light penetration deep inside. On the other hand, AzTo82 had apparently poor response to UV light. Namely, random orientation was not sufficiently induced by accumulation of cis isomers of $\mathrm{Az}$ groups. This is due to strong intermolecular interactions between To groups as described in our previous reports. ${ }^{28,29}$ It is also supported by the fact that the $T_{\mathrm{g}}$ of AzTo decreased less with an increase in the molar ratio of the mesogen group than that of AzToMe (Fig. 3). In contrast, the ToMe group is considered to be advantageous for random orientation because of the steric hindrance of the methyl group.

Reversible on-off switching of reflection was examined by the sequence of light irradiation by $436 \mathrm{~nm}$ visible light (for the out-of-plane orientation state; reflection $=\mathrm{OFF}$ ) and $365 \mathrm{~nm} \mathrm{UV}$ light following $546 \mathrm{~nm}$ visible light (for the random orientation state; reflection $=\mathrm{ON}$ ), as shown in Fig. 8. For photo-induced on-off switching, the reflection contrast of AzToMe91 was improved owing to a better orientation behavior and higher refractive index.
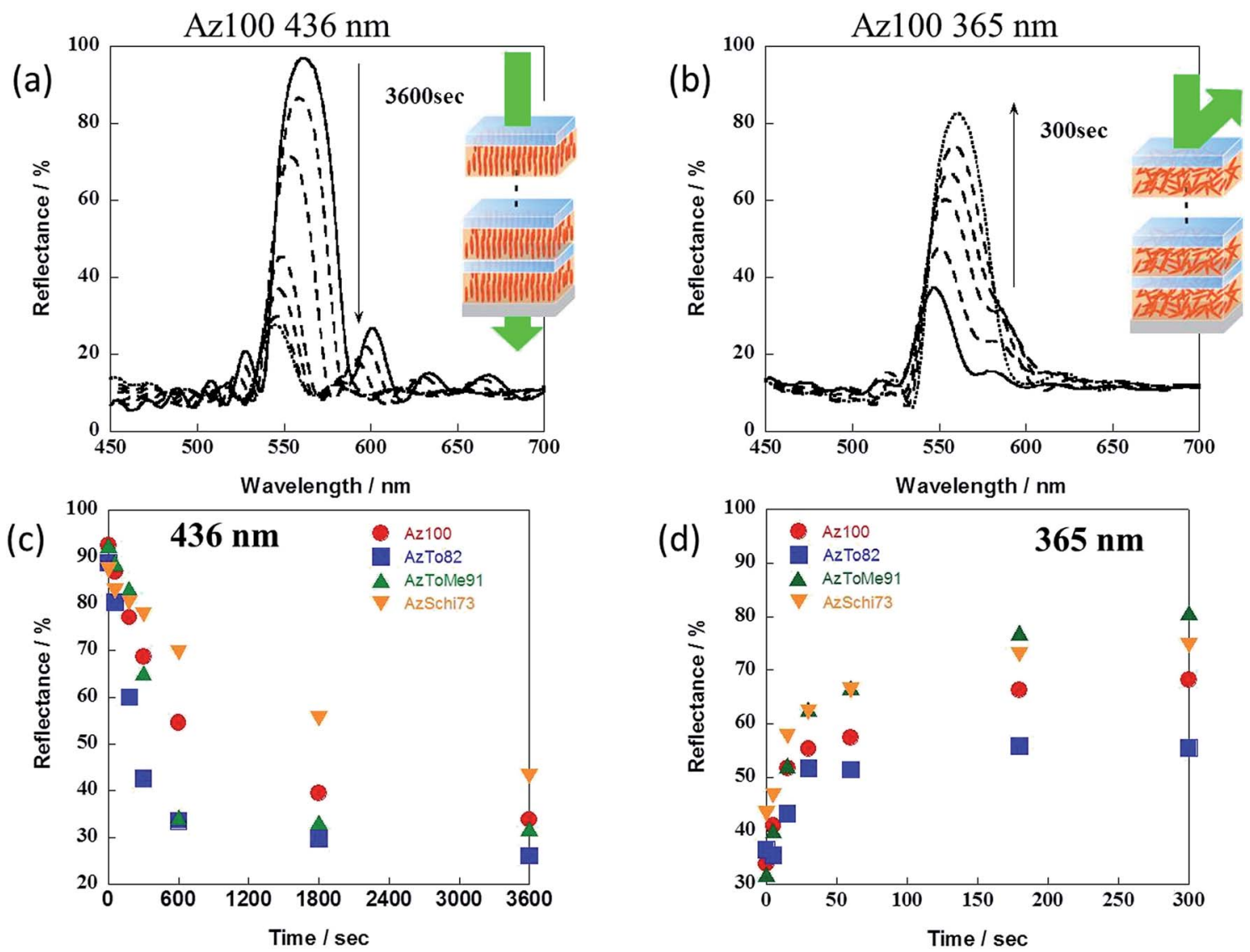

Fig. 7 The reflection spectra ( $a$ and b) and time dependency (c and d) of reflection of Az100 after $436 \mathrm{~nm}$ light ( $a$ and c) and $365 \mathrm{~nm}$ light (b and d). The orientation states of films are illustrated in the figures. 

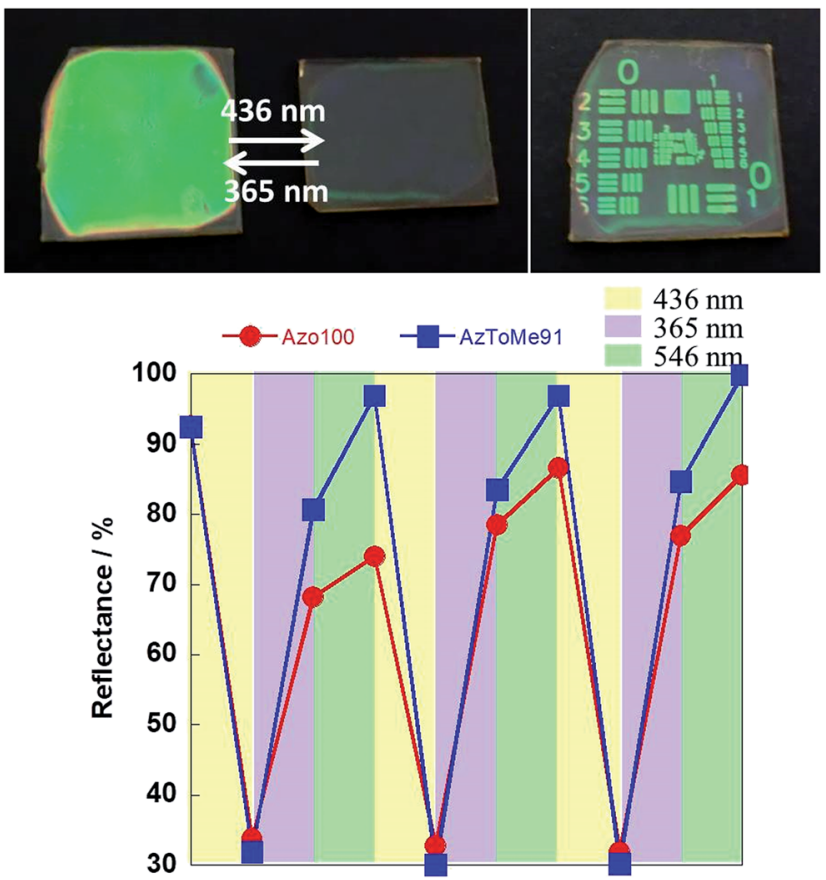

Fig. 8 Photos of on-off state of reflection and writing patterns on the multi bilayered film of AzTo(Me)91. Repeated examination for reflection changes of the muli-bilayered films by light irradiation at $436 \mathrm{~nm}$ (150 mW cm $\left.\mathrm{mW}^{-2}, 30 \mathrm{~min}\right), 365 \mathrm{~nm}\left(30 \mathrm{~mW} \mathrm{~cm}^{-2}, 10 \mathrm{~min}\right)$, and $546 \mathrm{~nm}$ (100 $\left.\mathrm{mW} \mathrm{cm}^{-2}, 10 \mathrm{~min}\right)$.

\section{Conclusion}

LC mesogen groups with long-conjugated systems were synthesized and the copolymers with the Az group and the LC groups showed higher refractive indices compared with that of Az100, except for the copolymers with the Schi group. For the thin films, the orientation states were controlled by irradiation of $365 \mathrm{~nm}, 436 \mathrm{~nm}$ and $546 \mathrm{~nm}$ light, except for the copolymers with the Stb group. For the multi-bilayered films comprising Azcontaining copolymers and PVA, photo-induced on-off switching of reflection was conducted. Reflectance and photo responses were improved compared to those of Az100 and the best performance was obtained for AzToMe91. The methyl group of ToMe relaxed the strong intermolecular interaction between To groups. For the copolymers with the Schi and Stb groups, the photo-responses were poor, possibly due to the higher surface energy and molecular rigidity, respectively.

\section{Conflicts of interest}

There are no conflicts to declare.

\section{References}

1 B. Comiskey, J. D. Albert, H. Yoshizawa and J. Jacobson, Nature, 1998, 16, 253-255.

2 Y. Chen, J. Au, P. Kazlas, A. Ritenour, H. Gates and M. McCreary, Nature, 2003, 8, 136.
3 P. Mach, P. Wiltzius, M. Megens, D. A. Weitz, K. Lin, T. C. Lubensky, et al., Europhys. Lett., 2002, 58, 679.

4 S. Kuai, G. Bader and P. V. Ashrit, Appl. Phys. Lett., 2005, 86, 221110.

5 S. W. Leonard, J. P. Mondia, H. M. van Driel, O. Toader, S. John, K. Busch, et al., Phys. Rev. B, 2000, 61, R2389-R2392.

6 C. I. Aguirre, E. Reguera and A. Stein, Adv. Funct. Mater., 2010, 20, 2565-2578.

7 A. C. Arsenault, D. P. Puzzo, I. Manners and G. A. Ozin, Nat. Photonics, 2007, 1, 468-472.

8 K. Busch and S. John, Phys. Rev. Lett., 1999, 83, 967-970.

9 S. O’Brien and J. B. Pendry, J. Phys.: Condens. Matter, 2002, 14, 4035.

10 J. Zhou, C. Q. Sun, K. Pita, Y. L. LAm, Y. Zhou, S. L. NAg, C. H. Kam, L. T. Li and Z. L. Gui, Appl. Phys. Lett., 2001, 78, 661-663.

11 K. Lee and S. A. Asher, J. Am. Chem. Soc., 2000, 122, 95349537.

12 K. Ueno, K. Matsubara, M. Watanabe and Y. Takeoka, Adv. Mater., 2007, 19, 2807-2812.

13 Y. J. Lee and P. Braun, Adv. Mater., 2003, 15, 563-566.

14 J. M. Weissman, H. B. Sunkara, A. S. Tse and S. A. Asher, Science, 1996, 274, 959-963.

15 J. H. Holtz and S. A. Asher, Nature, 1997, 389, 829-832.

16 R. A. Barry and P. Wiltzius, Langmuir, 2006, 22, 1369-1374.

17 Y. Takeoka and M. Watanabe, Langmuir, 2003, 19, 95549557.

18 R. Yagi, H. Katae, Y. Kuwahara, S. Kim, T. Ogata and S. Kurihara, Polymer, 2014, 55, 1120-1127.

19 M. Moritsugu, T. Ishikawa, T. Kawata, T. Ogata, Y. Kuwahara and S. Kurihara, Macromol. Rapid Commun., 2011, 32, 15461550.

20 T. Komikado, A. Inoue, K. Masuda, T. Ando and S. Umegaki, Thin Solid Films, 2007, 515, 3887-3892.

21 R. Yagi, H. Iwamoto, Y. Kuwahara, S. Kim, T. Ogata and S. Kurihara, RSC Adv., 2015, 5, 84762-84769.

22 S. Yoneyama, T. Yamamoto, O. Tsutsumi, A. Kanazawa, T. Shiono and T. Ikeda, Macromolecules, 2002, 35, 87518758.

23 S. D. Sarkar and B. Choudhury, Acta Phys. Pol., A, 2010, 118, 665-669.

24 F. Ye, A. Orita, J. Yaruva, T. Hamada and J. Otera, Chem. Lett., 2004, 33, 528-529.

25 M. S. Zakerhamidi, Z. Ebrahimi, H. Tajalli, A. Ghanadzadeh, M. Moghadam and A. Ranjkesh, J. Mol. Liq., 2010, 157, 119124.

26 K. Okano, A. Shishido and T. Ikeda, Adv. Mater., 2006, 18, 523-527.

27 T. Ikeda, S. Horiuchi, D. B. Karanjit, S. Kurihara and S. Tazuke, Macromolecules, 1990, 23, 36-42.

28 M. Moritsugu, T. Shirota, S. Kubo, T. Ogata, O. Sato and S. Kurihara, J. Polym. Sci., Part B: Polym. Phys., 2009, 47, 1981-1990.

29 T. Shirota, M. Moritsugu, S. Kubo, T. Ogata, T. Nonaka, O. Sato, et al., Mol. Cryst. Liq. Cryst., 2009, 513, 79-88.

30 N. Tanio and M. Irie, Jpn. J. Appl. Phys., Part 1, 1994, 33, 3942. 
31 I. Zebger, M. Rutloh, U. Hoffmann, J. Stumpe, H. W. Siesler and S. Hvilsted, J. Phys. Chem. A, 2002, 106, 3454-3462.

32 M. Han, S. Morino and K. Ichimura, Macromolecules, 2000, 33, 6360-6371.

33 O. V. Yaroshchuk, A. D. Kiselev, Y. Zakrevskyy, T. Bidna, J. Kelly, L. Chien, et al., Phys. Rev. E: Stat., Nonlinear, Soft Matter Phys., 2003, 68, 011803.

34 K. Ichimura, M. Han and S. Morino, Chem. Lett., 1999, 28, 85-86.
35 T. Ikeda, J. Mater. Chem., 2003, 13, 2037-2057.

36 A. Shishido, Polym. J., 2010, 42, 525-533.

37 A. V. Bogdanov and A. K. Vorobiev, J. Phys. Chem. B, 2013, 117, 13936-13945.

38 S. P. Palto and G. Durand, J. Phys. II, 1995, 5, 963-978.

39 Y. Wu, Y. Demachi, O. Tsutsumi, A. Kanazawa, T. Shiono and T. Ikeda, Macromolecules, 1998, 31, 349-354. 